\title{
Conhecendo a Biblioteca Pública Arús
}

Paulo Pinheiro Machado*

Resumo: O presente artigo tem como finalidade apresentar aos pesquisadores brasileiros a Biblioteca Pública Arús, localizada em Barcelona - Espanha -, tratando da formação e história dessa instituição, a evolução de seu acervo e sua importância para os estudos sobre movimento operário europeu e latino-americano na virada do século XIX ao XX.

Palavras-chave: Biblioteca Pública Arús. Operários. Anarquismo. Socialismo.

\section{O fundador}

Definitivamente tenho me agrupado entre os que desejam a única forma de governo possível, onde somente com a comunhão política pode se alcançar o engrandecimento e a prosperidade da Pátria; ao nobre e honrado Partido Republicano Democrático Federal. (ARÚS i ARDERIU, 1873, p. 2, tradução minha).

* Professor do Departamento de História da Universidade Federal de Santa Catarina (UFSC).E-mail: pmachado@mbox1.ufsc.br. 
Rossend Arús i Arderiu foi um personagem curioso. Cronista, teatrólogo, humorista e livre-pensador, viveu entre 1845 e 1891, em Barcelona, Espanha. O texto citado acima é a abertura da peça de teatro de sua autoria, intitulada Monarquia nunca mais! Filho de família abastada, Arús deixou a administração de seus negócios a um empregado de confiança e dedicou-se a escrever peças (mais de 50), a divulgar a língua catalã, a fundar periódicos e contribuir com crônicas - de humor, crítica política e de costumes - para muitas revistas na Espanha e no exterior. Juntou-se a outros intelectuais que - na segunda metade do século XIX - transformaram Barcelona no centro do movimento do renascimento da cultura e da língua catalãs. Arús defendia uma república federalista, laica e democrática e, embora não tenha se filiado formalmente a um partido político específico, foi um dos primeiros a apoiar a proclamação da Primeira República em Barcelona, em 1873.

$\mathrm{Na}$ segunda metade do século XIX Barcelona já era um centro industrial, especialmente desenvolvido no ramo têxtil. A cidade vivia os conflitos em torno das lutas por redução de jornada de trabalho, melhores salários, descanso semanal e limitação dos horários de mulheres e crianças. Desde cedo Barcelona foi um centro importante de lutas operárias e democráticas. Na primeira metade do século XIX foi palco de movimentos de tipo luddista, participou das erupções revolucionárias de 1848 e das jornadas a partir de 1869 que resultaram na formação da Primeira República em 1873.

A geração de Rossend Arús criou-se dentro de um forte sentimento democrático e anticlerical, tendo como meio de divulgação jornais, clubes republicanos e lojas maçônicas. Arús foi seguidor político de Francesc Pi i Margall, um republicano federalista que chegou a ser ministro em 1873. O federalismo era força hegemônica na Catalunha e sua vertente republicana, embora não majoritária no início, crescia rapidamente. Margall e Rossend Arús entendiam que a república federativa era o melhor sistema para a garantia das liberdades e das autonomias regionais, como no caso da Catalunha. Defendiam o voto universal, a igualdade de todos frente à lei, a liberdade de imprensa, a liberdade religiosa, a liberdade de ensino e de associação. $O$ federalista catalão Coroleu, que conheceu Margall e Arús, definiu o último como "um republicano 
por convicção, democrata por instinto e, em seu conceito, a República e a Democracia significavam para o povo a redenção frente à escuridão da ignorância e dos martírios da miséria" (ILLA MUNÉ, 1987, p. 522, tradução minha).

Um pouco antes de morrer, Rossend Arús doou todos os seus bens ao povo de Barcelona e recomendou, a dois amigos que foram os executores de sua derradeira vontade - Valentí Almirall e Anton Farnés -, que se organizasse uma biblioteca pública. Em 1895, quatro anos após a morte de Arús, seus amigos abriram ao povo de Barcelona essa biblioteca. Além do acervo bibliográfico pessoal de Arús, que contava com quatro mil livros, os organizadores adquiriram, por compra e doação, mais de 20 mil obras.

\section{A biblioteca}

A própria residência de Arús foi transformada em sede do estabelecimento, que passou a ser de propriedade perpétua do povo de Barcelona. Seu endereço é no bairro de Eixample, no Passeig de Saint Joan, $\mathrm{n}^{\circ}$ 26. A transformação da residência em biblioteca pública demandou muitas obras, como a construção das salas de leitura, com mesas de madeira maciça de alta qualidade (com inclinação para melhor conforto do leitor), iluminação moderada e estantes por várias peças. Na sala de leituras principal há a inscrição de destacados nomes da literatura, das artes e do pensamento em geral: Shakespeare, Sófocles, Ésquilo, Maomé, Petrarca, Camões, Moisés, Galileu, Bacon, Darwin, Averróis, Platão, Descartes, Renan, Homero, Humboldt, Heródoto, Tucídides, Júlio Verne e outros.

O pé-direito possui mais de quatro metros, os pisos são de mármore e madeira, as luminárias, de bronze trabalhado. A ideia dos organizadores é que uma biblioteca aberta ao povo deveria ser um local solene, luxuoso e agradável. No primeiro catálogo do acervo, publicado na época da inauguração da instituição, há uma espécie de declaração de princípios da biblioteca: seu acervo será sempre livre e diversificado, sendo proibida a exclusão - por motivos 
sociais, religiosos ou políticos - de qualquer gênero de livro; além disso, não se poderá impedir a entrada nem o acesso aos meios de leitura a qualquer pessoa, independentemente de sexo, idade ou classe social.

A composição do acervo da biblioteca revela o ecletismo do seu inspirador e dos seus amigos que deram sequencia ao projeto. Arús tinha um grande acervo de livros de viagem, de exploradores que andaram por todos os continentes. Dos viajantes que andaram pelo Brasil estão presentes no acervo Ferdinand Denis, Charles Expilly, Leonce Aubé, S. Dutot, Marie Hilaire Tapie, Jean-Jacques Brousson, Alcide Orbigny e outros. Além dos viajantes, as principais obras sobre o Brasil são do incansável Edgard Rodrigues. Há importantes edições de autores clássicos da literatura e do teatro, dos séculos XVII, XVIII e XIX (Rousseau, Montesquieu, Molière, Malarmé, Balzac, Victor Hugo). Apesar da forte influência maçônica, os livros dedicados a esse assunto não são muito representativos do acervo e autores ligados ao catolicismo, como Tomás de Aquino e Santo Agostinho, estão presentes.

\section{O acervo}

Durante as décadas iniciais do século XX o acervo foi acrescido de coleções de revistas, cartazes e panfletos de sindicalistas, socialistas, anarquistas e comunistas. Hoje se trata do principal acervo espanhol desses periódicos operários. Há longas coleções de periódicos de sindicatos por categorias, como tecelões, marinheiros, mineiros, metalúrgicos, ferroviários, portuários, como também de centrais sindicais como a UGT (Unión General de los Trabajadores, ligada aos socialistas), a CNT (Central Nacional de los Trabajadores, ligada aos anarquistas) e as CCOO (Comisiones Obreras, ligadas aos comunistas). Além disso, há publicações de organizações de trabalhadores franceses, ingleses, italianos, belgas, alemães, russos, mexicanos, argentinos, norte-americanos, canadenses, húngaros e de outras nacionalidades. Grande acervo de periódicos comunistas está disponível, desde as publicações do PCE (Partido Comunista Espanhol), do Comitê Central e de diferentes 
províncias, como de dissidências nos diversos grupos ligados à IV Internacional (trotskistas) e o POUM (Partido Obrero de Unificación Marxista).

Durante a Guerra Civil a biblioteca serviu como local de alojamento para republicanos refugiados de outras regiões da Espanha que estavam sob domínio franquista e, em finais de 1938 deixou de atender ao público e esteve fechada ao longo de quase todo regime ditatorial de Franco. Em 1967 há a reativação de seu conselho e reabertura discreta ao público. Mas só em 1974, com a participação do professor Josep Fontana, a biblioteca é reformada e reinaugurada nos tempos finais da ditadura. Além da reforma física do prédio, é realizado um novo inventário do acervo e, ao longo dos anos seguintes à redemocratização espanhola, é acrescido ao acervo um grande número de periódicos e publicações de organizações operárias e de esquerda que viveram por décadas no exílio. Portanto, além das publicações operárias espanholas no final do século XIX e início do XX, há um número não desprezível de periódicos de espanhóis em Buenos Aires, Montevidéu, Paris, Londres, Nova Iorque, Chicago, Havana, Cidade do México, Santiago do Chile e outras, num período que vai da década de 1930 a 1980.

Hoje a Biblioteca Pública Arús está em vias de informatizar o conjunto de seu catálogo. Por enquanto, já podem ser acessados pelo sistema de busca das Bibliotecas da Catalunha (http:// www.cbuc.cat/institucions/bpa/) todos os livros com data posterior a 1901. Em breve o catálogo de periódicos, que já existe impresso, e o restante do acervo, estarão disponíveis on-line. Por enquanto a consulta ao sistema de referência é manual, com fichários organizados por título, por autor e por assunto (matérias). Há um catálogo manual de periódicos por data, mas não é completo, melhor procurar periódicos pelo catálogo impresso. Mas o leitor deve estar atento para o fato da classificação por assuntos estar em língua catalã que, apesar da proximidade com o castelhano, tem lá suas particularidades. Se estiver procurando por greve, por exemplo, não achará "huelga", mas poderá localizar pela palavra catalã "vaga" (no plural "vagues"). O site da biblioteca é http://www.bpa.es. Nesse local o leitor interessando tem todas as informações sobre 
horários de funcionamento e credenciamento para consulta. Atualmente a biblioteca é mantida pelo governo muni-cipal de Barcelona (Ajuntament) e o leitor precisa se cadastrar e pagar uma taxa de 20,00 euros para utilizar a biblioteca por três anos.

\section{Os periódicos}

Entre as revistas o acervo é também muito diversificado. Há periódicos da área de medicina, homeopatia, engenharia, ciências sociais, poesia e crítica literária, em grande parte do final do século XIX e início do XX. Há jornais raríssimos, como o Diario de Barcelona, publicado de 1792 até 1810 . Há periódicos governamentais e veículos da grande imprensa. Mas é inegável a presença hegemônica da imprensa operária, sindical e de esquerda em geral.

A coleção de periódicos da Biblioteca Arús possui muito pouco material publicado no Brasil. Há dois números d'O Archote, de Niterói, de 1947; um exemplar da Tribuna Livre, de Bagé, 1926; um exemplar do jornal anticlerical $A$ Lanterna, de São Paulo, 1953; um exemplar d'O Libertário, de São Paulo, 1962; 120 exemplares da revista de cooperativismo Arco-Íris, do Rio de Janeiro (entre 1955 e 1969); 33 números do periódico anarquista $A$ Plebe, de São Paulo, de 1934, e de 1947 a 1951 . A coleção mais completa é do Ação Direta, semanário anarquista do Rio de Janeiro, com números de 1946 a 1959, com poucas lacunas.

O número de periódicos platinos, por outro lado, é elevado. Somando as revistas originárias de Buenos Aires, Montevidéu, Rosário, Mendoza, Tucumán, Santa Fé e La Plata, são 234 periódicos. Muitos com poucos exemplares, mas algumas coleções que atravessam vários anos, como La Protesta, jornal anarquista portenho que possui uma coleção que, com algumas poucas interrupções, abrange o período de 1922 a 1976. Há jornais platinos que são claramente produto de exilados da Guerra Civil vencida por Franco, como o Lealtad, "órgano de la democracia española", publicado em Montevidéu entre 1944 e 1957, e o Correo de Asturias, "periódico republicano español, informativo y independiente", publicado em Buenos Aires entre 1941 e 1946. Os republicanos 
exilados esperavam, com a vitória aliada que ficou mais clara a partir da batalha de Stalingrado, uma iminente queda do regime franquista. Isso fez com que publicações republicanas espanholas ocorressem em grande número entre 1943 e 1947, ao largo de muitos países da diáspora. A Guerra Fria que se seguiu frustrou essa esperança. Os governos ocidentais permitiram a sobrevivência do fascismo ibérico (MOLINERO, 2008).

A longa imigração espanhola para a América foi reforçada com a presença de republicanos exilados. Alguns periódicos representam essa sucessão de migrantes, como o caso do Cultura Proletária, publicado em Nova Iorque, sendo que a Biblioteca Arús possui exemplares de 1927 a 1953. A presença de periódicos espanhóis publicados nos Estados Unidos é muito forte, há também o España Libre, igualmente publicado em Nova Iorque (19441962).

Analisando a Biblioteca Pública Arús e a trajetória de seu acervo, podemos considerar que ela é um retrato da própria história da democracia e dos movimentos sociais da Espanha. Sofreu com a Guerra Civil e a longa ditadura, mas recompôs seus recursos e retomou sua trajetória a partir de meados dos anos 1970.

\section{Knowing the Public Library Arús}

Abstract: This article aims to introduce Brazilian researchers with Public Library Arús, in Barcelona - Spain - dealing with the formation and history of this institution, the development of its collection and its importance to studies of European and Latin American labor movement at the turn of the twentieth century. Keywords: Public Library Arús. Workers. Anarchism. Socialism.

\section{Referências}

ARÚS i ARDERIU, R. May més monarquia!: actualitat política em um acte y 'n vers catalá. Barcelona: Imprensa de Sant Manero, 1873.

ILLA i MUNÉ, M. D. C. Biblioteca Pública Arús. In: BENIMELLI, J. A. F. (Org.). La masonería en La España del siglo XIX. Volumen 1.Valladolid: Junta de Castilla y León, 1987. 


\section{Conhecendo a Biblioteca Pública Arús}

MOLINERO, C. La anatomía del Franquismo: de la supervivencia a la agonía: 19451977. Barcelona: Crítica, 2008.

Recebido em: 16/03/2010

Aprovado em: 05/06/2010 